\title{
Morphology and Crystallography of Martensite Plate with Long Period Stacking Structure in Ti-Pd Shape Memory Alloy
}

\author{
Mitsuhiro Matsuda ${ }^{1}$, Shoichiro Yano ${ }^{1, *}$ and Minoru Nishida ${ }^{2}$ \\ ${ }^{1}$ Department of Materials Science and Engineering, Kumamoto University, Kumamoto 860-8555, Japan \\ ${ }^{2}$ Department of Applied Science for Electronics and Materials, Kyushu University, Kasuga 816-8580, Japan
}

\begin{abstract}
The morphology and crystallography of martensite plates with a long period stacking structure in Ti-Pd shape memory alloy were investigated by transmission electron microscopy. In addition to B19 $(2 \mathrm{H})$ martensite, an $18 \mathrm{R}(2 \overline{1})_{6}$ structure was observed in equiatomic Ti-Pd alloy quenched above $1373 \mathrm{~K}$. Three fundamental plate variant combinations were identified in the plate group in the region consisting exclusively of 18R martensite. These were designated A : B, A : C and A : D types, and their morphologies and crystallographic characteristics are a wedge with type II, a spear with type I and a fork with compound twin relations, respectively. Duplex martensitic phases coexisting in the same area, namely, "two-in-one" structures, were also observed. [doi:10.2320/matertrans.M2011187]
\end{abstract}

(Received June 20, 2011; Accepted August 10, 2011; Published September 28, 2011)

Keywords: titanium-palladium alloy, martensitic transformation, $18 R$ martensite, variant accommodation twin, transmission electron microscopy

\section{Introduction}

Ti-Pd alloys of near-equiatomic composition are promising materials for high temperature shape memory alloys, because they undergo a thermoelastic martensitic transformation from a B2 to a $2 \mathrm{H}$ (B19) structure at around $800 \mathrm{~K}$ upon cooling. ${ }^{1)}$ The microstructures of martensites in this alloy have previously been studied by conventional transmission electron microscopy (CTEM), high-resolution transmission electron microscopy (HRTEM), and high-angle annular dark-field scanning transmission electron microscopy. ${ }^{2-4)}$ The internal defects of the $2 \mathrm{H}$ martensite in the Ti-Pd alloy that have been confirmed so far are $\{111\}_{2 \mathrm{H}}$ Type I, $\langle 121\rangle_{2 \mathrm{H}}$ Type II, and $\{101\}_{2 \mathrm{H}}$ compound twinnings. ${ }^{3)}$ The $\{111\}_{2 \mathrm{H}}$ Type I and $\langle 121\rangle_{2 \mathrm{H}}$ Type II twinnings, which are conjugate to one another, coexist in the same martensite variant. The $\{111\}_{2 \mathrm{H}}$ Type I twinning is considered to be a lattice invariant shear of the martensitic transformation, whereas the others are defined as deformation twins due to the elastic interactions during the transformation rather than a lattice invariant shear.

In addition to the microstructural analysis, a new phase diagram of the Ti-Pd binary system has been proposed by one of the present authors. ${ }^{5)}$ However, there is still a lack of sufficient information about the phase equilibrium in nearequiatomic Ti-Pd alloy, especially in the high temperature region above $1273 \mathrm{~K}$. We therefore investigated specimens quenched above $1273 \mathrm{~K}$ to obtain the microstructural aspects at high temperatures. As a result of microstructural observations at room temperature, we fortuitously discovered a martensitic phase with a long period stacking structure in near-equiatomic Ti-Pd alloys quenched at temperatures above $1373 \mathrm{~K}$. The martensite with a long period stacking structure in the Ti-Pd binary system has not been reported so far. It is widely recognized that the lattice invariant shear of martensite with long period stacking structures, such as $9 \mathrm{R}$ or

*Graduate Student, Kumamoto University
18R martensite, is a stacking fault on the (001) basal plane. ${ }^{6)}$ Therefore, the internal twins are boundaries of martensite plate variants, the so-called "variant accommodation twinning". ${ }^{7-9)}$ Variant accommodation twinning is introduced as a result of mutual accommodation of shear strains between variants in the martensite. For $9 \mathrm{R}$ and/or $18 \mathrm{R}$ martensite, several researchers have reported that there are four plate variants, commonly designated A, B, C and D, and that three fundamental plate variant combinations can be identified in a given plate variants. These are designated $\mathrm{A}: \mathrm{B}, \mathrm{A}: \mathrm{C}$ and A : D types around one of $\{110\}$ poles in the parent phase. ${ }^{7-10)}$ The intervariant boundaries of these three types are in Type II, Type I, and compound twin relations, respectively. ${ }^{11)}$

We performed a structural analysis of the newly discovered martensite with the long period stacking structure in the Ti-Pd alloy with the aim of clarifying both the morphological and crystallographic features of variant accommodation twins. The possibility of structural change in the parent phase at high temperature is also discussed in relation to the origin of the formation of martensite with a long period stacking structure.

\section{Experimental Procedure}

Ti-50.0 at\% Pd alloy was prepared from 99.7 mass $\% \mathrm{Ti}$ and 99.8 mass\% Pd by arc melting in an argon atmosphere. The ingots were homogenized in a vacuum at $1273 \mathrm{~K}$ for $36 \mathrm{ks}$. The rod of $3 \mathrm{~mm}$ in diameter was spark cut from the ingot and then cut into disks of $0.2 \mathrm{~mm}$ in thickness. These disks were solution-treated in a vacuum at temperatures from 1373 to $1423 \mathrm{~K}$ for $3.6 \mathrm{ks}$ then quenched into ice water. Differential scanning calorimetry (DSC) measurements were performed at a cooling and heating rate of $20 \mathrm{~K} / \mathrm{min}$. TEM specimens were mechanically polished, dimpled, and then finished by ion milling. CTEM and HRTEM observations were carried out using JEM-2000FX and FEI-Tecnai20F microscopes, respectively, with an accelerating voltage at 


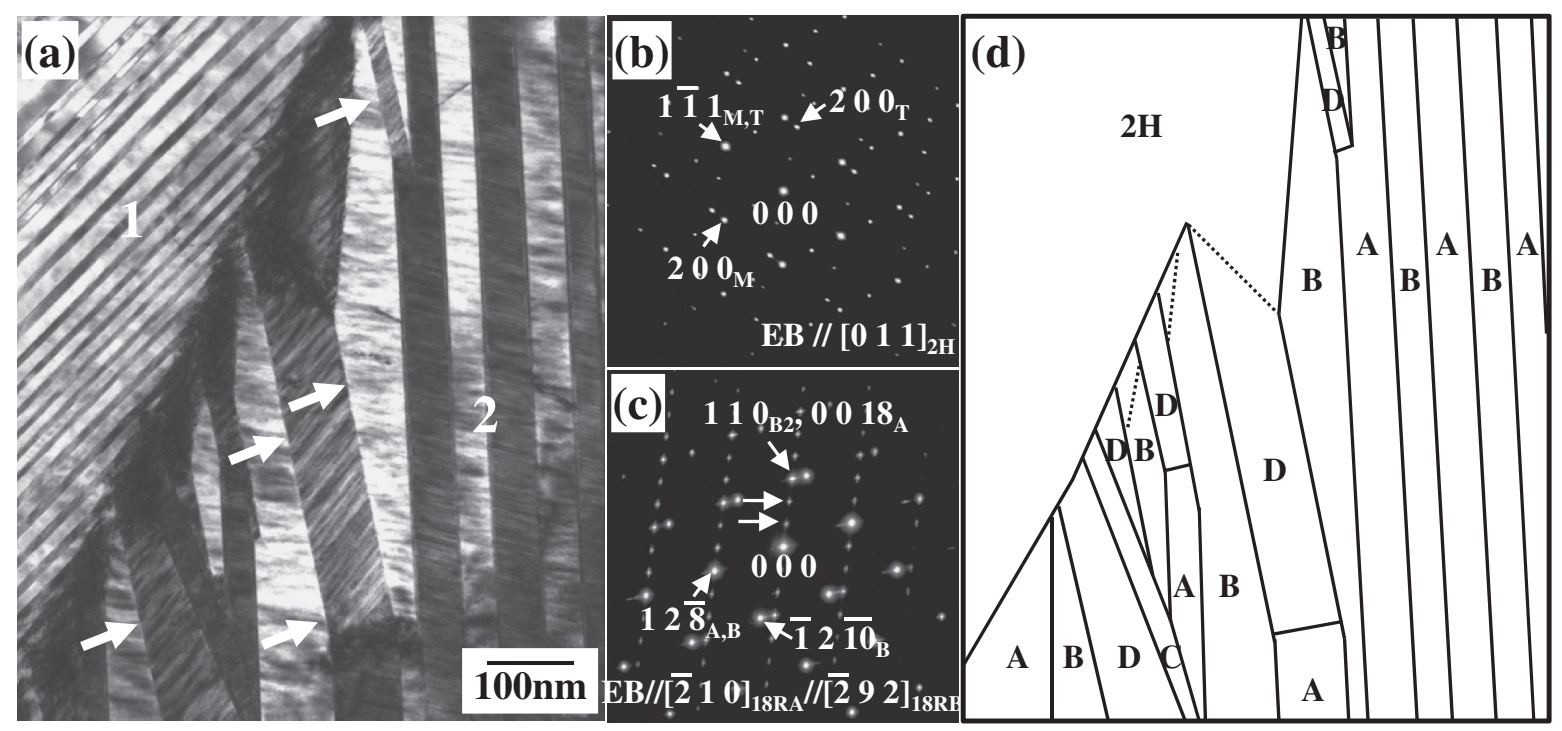

Fig. 1 (a) A bright field image of the typical morphology of the martensite in equiatomic Ti-Pd alloy quenched from $1423 \mathrm{~K}$. (b) and (c) Corresponding electron diffraction patterns taken from areas 1 and 2 , showing a $(1 \overline{1} 1)_{2 \mathrm{H}}$ Type I twin, and a Type II twin, respectively, in long period martensite. (d) Schematic illustration of the plate group configuration in (a).

$200 \mathrm{kV}$. The following lattice parameters of the $2 \mathrm{H}$ martensite were referred for the analysis of the martensite with a long period stacking structure: $a_{2 \mathrm{H}}=0.489 \mathrm{~nm}, b_{2 \mathrm{H}}=$ $0.281 \mathrm{~nm}$ and $c_{2 \mathrm{H}}=0.456 \mathrm{~nm}^{12}$ )

\section{Results and Discussion}

\subsection{Characteristic features of martensite}

Figure 1(a) shows the typical morphology of the martensite in the equiatomic Ti-Pd alloy quenched from $1423 \mathrm{~K}$. There are two kinds of martensite variants with different morphologies with respect to the size of martensite platelets in areas 1 and 2 , with each martensite variant consisting of alternating platelets with a regular spacing. The platelets in area 1 were identified as $\{1 \overline{1} 1\}_{2 \mathrm{H}}$ Type I twins by means of the corresponding electron diffraction pattern shown in Fig. 1(b). The pattern consists of two sets of reflections from the $[011]_{2 \mathrm{H}}$ zone axis that are in mirror symmetry with respect to the $(1 \overline{1} 1)_{2 \mathrm{H}}$ plane. The $\{1 \overline{1} 1\}_{2 \mathrm{H}}$ Type I twins are considered to be a lattice invariant shear of the present $\mathrm{B} 2$ to $2 \mathrm{H}$ transformation. ${ }^{2,3)}$ The platelets in area 2 have two characteristic features, as deduced from the corresponding electron diffraction pattern shown in Fig. 1(c). The first is the existence of a long period stacking structure, because there are some extra spots with regular intervals between the transmission beam and the spot corresponding to the $\{110\}$ plane of B2 parent phase, as indicated by the arrows. This long period stacking structure is $18 \mathrm{R}$ structure described below. The second characteristic is considered to be the Type II twin, because the traces of the stacking faults within the martensite platelets are not in mirror symmetry with respect to the platelet boundary in the area 2 of Fig. 1(a). Furthermore, there are inclined platelets in which traces of the stacking faults on the basal plane are in mirror symmetry to the boundary of the platelets, as indicated by the arrows in Fig. 1(a). These combinations correspond to the Type I twin relation discussed below. From the identification of martensite variants by means of electron diffraction experiments,

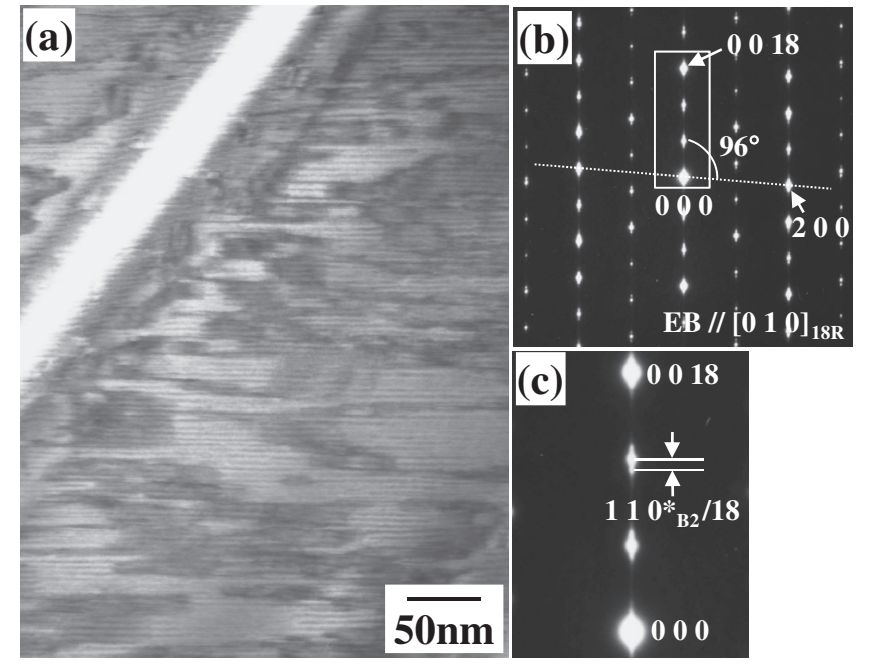

Fig. 2 (a) and (b) A bright field image and the corresponding electron diffraction pattern for the $18 \mathrm{R}$ structure in euiatomic Ti-Pd alloy quenched from 1383 K. (c) Enlargement of the framed area in (b).

most of plate boundaries in Fig. 1(a) were characterized as illustrated in Fig. 1(d), although there are some uncertain boundaries, indicated by dotted lines, around the border area of the $2 \mathrm{H}$ and $18 \mathrm{R}$ martensites. Three fundamental plate variant combinations; that is, $\mathrm{A}: \mathrm{B}$ or $\mathrm{C}: \mathrm{D}, \mathrm{A}: \mathrm{C}$ or $\mathrm{B}: \mathrm{D}$, and $\mathrm{A}: \mathrm{D}$ or $\mathrm{B}: \mathrm{C}$ types, were therefore clearly recognized in the plate group of the $18 \mathrm{R}$ martensite. The confirmation of these analyses is discussed in Sections 3.2-3.4.

\subsection{Stacking structure of martensite}

Figure 2(a) shows the bright field image taken along the $[010]_{18 \mathrm{R}}$ direction as indicated by corresponding electron diffraction pattern shown in Fig. 2(b). The pattern corresponds to another low-index zone axis parallel to the basal plane of martensite with a long period stacking structure. The extra spots are located exactly at every $1 / 18$ position between the transmission beam and the spot corresponding to the 
$\{110\}_{\mathrm{B} 2}$, as shown in the enlarged pattern in Fig. 2(c). The spot distribution on both sides of the $c^{*}$ axis is asymmetric, as indicated by the dotted line in Fig. 2(b). This fact suggests that the long period stacking structure is not in mirror symmetry with respect to the basal plane. In other words, the stacking structure belongs to the R-type not but the H-type. ${ }^{6}$ Figure 3 shows a two-dimensional lattice image of the long period stacking structure and a schematic of the unit cell. A certain periodicity at every 18 layers can be clearly seen. The stacking sequence does not have mirror symmetry with respect to the basal plane as expected from Fig. 2(b) and therefore the angle between $(100)_{18 \mathrm{R}}$ and $(001)_{18 \mathrm{R}}$ planes is $84^{\circ}$. From these features, the long period stacking structure is determined to be of the $18 \mathrm{R}(2 \overline{1})_{6}$ structure. The lattice parameters of the $18 \mathrm{R}$ martensite, estimated from the electron diffraction experiments, are as follows: $a=$ $0.49 \mathrm{~nm}, b=0.57 \mathrm{~nm}, c=4.25 \mathrm{~nm}$, and $\beta=84^{\circ}$. It is therefore definitely confirmed that equiatomic Ti-Pd alloy quenched at above $1373 \mathrm{~K}$ contains a martensite with an $18 \mathrm{R}(2 \overline{1})_{6}$ structure in addition to one with a $2 \mathrm{H}$ structure.
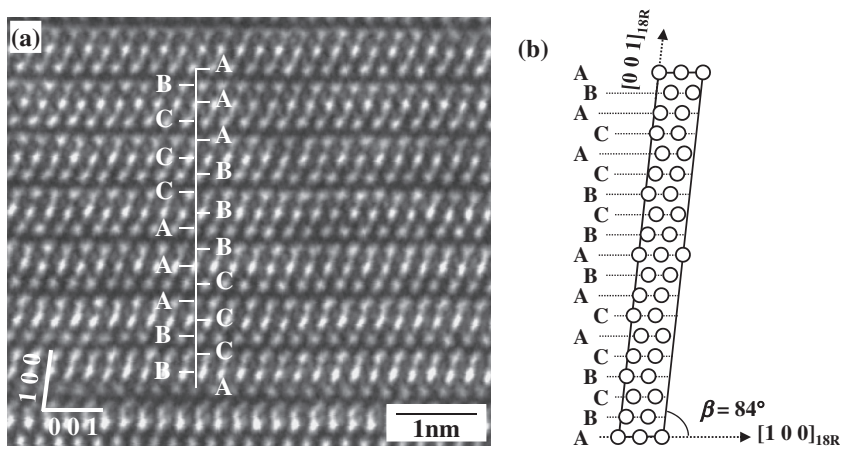

Fig. 3 (a) Two-dimensional lattice image of the $18 \mathrm{R}(2 \overline{1})_{6}$ strucure. (b) Schematic illustration of the unit cell.

\subsection{Combination of $18 \mathrm{R}$ martensite plate}

Figure 4(a) shows a bright field image of the region consisting exclusively of $18 \mathrm{R}$ martensitic plates, taken along the $\left[\begin{array}{lll}10 & 9 & 1\end{array}\right]_{18 \mathrm{R}}$ direction. Figures $4(\mathrm{~b})$ and (c) are selected area electron diffraction patterns taken from areas 1 and 2 , respectively, in Fig. 4(a). The pattern in Fig. 4(b) consists of two sets of reflections of the $\left[\begin{array}{lll}\overline{10} & 9 & 1\end{array}\right]_{18 \mathrm{R}}$ zone axis that are in mirror symmetry with respect to the $(12 \overline{8})_{18 \mathrm{R}}$ plane. The alternating platelets in area 1 can be concluded to be $(12 \overline{8})_{18 \mathrm{R}}$ Type I twins, i.e., A : C type. On the other hand, Fig. 4(c) shows a single pattern of the $\left[\begin{array}{lll}\overline{10} & 9 & 1\end{array}\right]_{18 \mathrm{R}}$ zone axis. The single pattern taken from alternating platelets is a characteristic of Type II twin along the $\eta_{1}$ direction. In other words, the patterns from the matrix and the twin are related by a rotation of $\pi$ around the $\eta_{1}=\left[\begin{array}{lll}\overline{10} & 9 & 1\end{array}\right]_{18 \mathrm{R}}$ axis. The platelets in area 2 are therefore considered to be in a [ $\overline{10} 91]_{18 \mathrm{R}}$ Type II twin relation, i.e., A : B type. We can clearly see spear and wedge morphologies at the $\mathrm{A}: \mathrm{C}$ and the $\mathrm{A}: \mathrm{B}$ type boundaries, respectively. All plate boundaries seen in Fig. 4(a) are characterized as illustrated in Fig. 4(d). A : D and B : C type boundaries are expected to be $\left(\begin{array}{lll}1 & 0 & 10\end{array}\right)_{18 \mathrm{R}}$ compound twins, since their boundaries are on the $\left(\begin{array}{lll}1 & 0 & 10\end{array}\right)_{18 \mathrm{R}}$ plane according to the patterns shown in Figs. 4(b) and (c). However, it is difficult to identify the boundaries precisely within small areas by electron diffraction experiments. Therefore, another example of a plate boundary was analyzed, as shown in Fig. 5(a). The pattern in Fig. 5(b), taken from area 1 of Fig. 5(a), consists of two sets of reflection from the $[010]_{18 \mathrm{R}}$ zone axis that are in mirror symmetry with respect to the $\left(\begin{array}{lll}1 & 0 & 10\end{array}\right)_{18 \mathrm{R}}$ plane. Thus, the plane defects crossing martensite plates in area 1 can be considered to be the $\left(\begin{array}{lll}1 & 0 & 10\end{array}\right)_{18 \mathrm{R}}$ compound twin, i.e., A : D type showing a kink morphology, as indicated by Fig. 5(c). From these results, three fundamental plate variant combinations can be identified in the given plate variants.
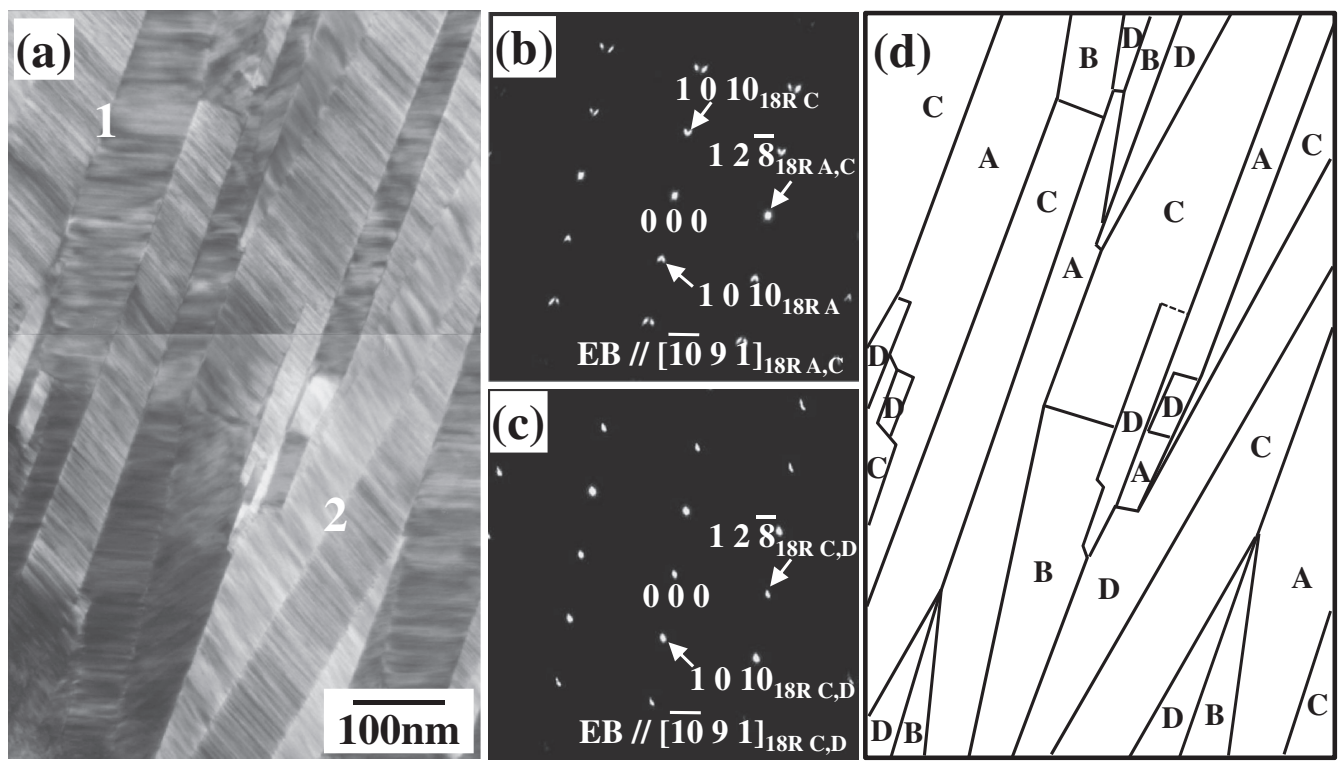

Fig. 4 (a) A bright field image of martensite variants consisting exclusively of $18 \mathrm{R}$ martensite in Ti-Pd alloy quenched from $1383 \mathrm{~K}$. (b) and (c) Corresponding electron diffraction patterns taken from areas 1 and 2 , showing $(12 \overline{8})_{18 \mathrm{R}}$ Type I and $\langle\overline{10} 91\rangle_{18 \mathrm{R}}$ Type II twinning, respectively. (d) Schematic illustration of the plate group configuration in (a). 


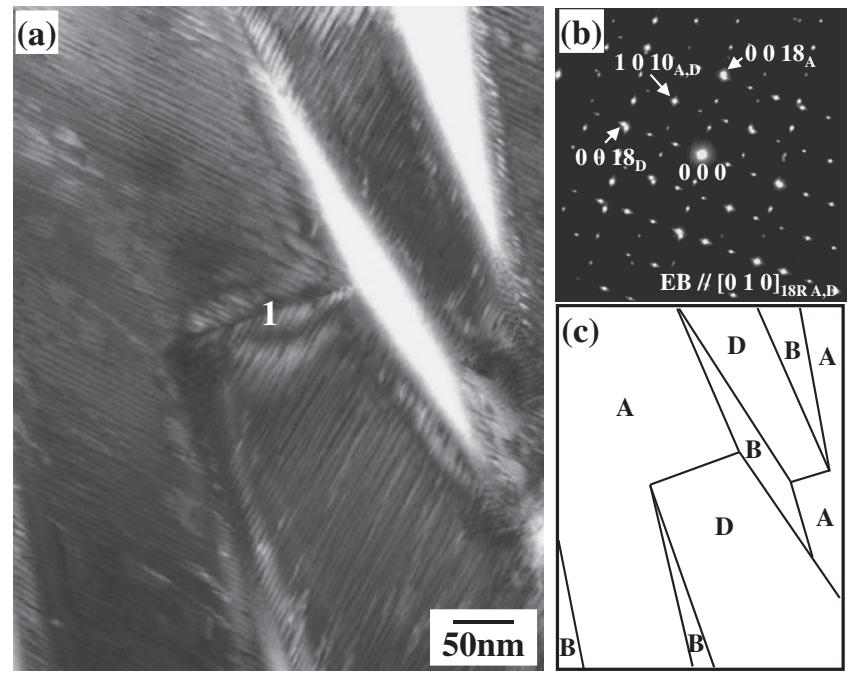

Fig. 5 (a) Another example of martensite variants consisting exclusively of 18R martensite in Ti-Pd alloy quenched from $1403 \mathrm{~K}$. (b) Corresponding electron diffraction pattern taken from area 1 showing $\left(\begin{array}{lll}1 & 0 & 10\end{array}\right)_{18 \mathrm{R}}$ compound twinning. (c) Schematic illustration of the plate group configuration in (a)
We have therefore identified three twinning modes in the 18R martensite of Ti-Pd alloy: $\{12 \overline{8}\}_{18 \mathrm{R}}$ Type I, $\langle\overline{10} 91\rangle_{18 \mathrm{R}}$ Type II, and $\left(\begin{array}{lll}1 & 0 & 10\end{array}\right)_{18 \mathrm{R}}$ compound twins. The twinning elements of each twinning mode in the $2 \mathrm{H}$ and $18 \mathrm{R}$ martensites, as calculated by the Bilby-Crocker theory, ${ }^{13)}$ are listed in Table 1.

\subsection{Two-in-one morphology}

When the duplex martensitic phases coexist in the same area, a unique microstructure, termed as a "two-in-one" morphology, is known to form in several alloy systems. ${ }^{14,15)}$ A typical example of a "two-in-one" structure is shown in Fig. 6(a). Figures 6(b) to (d) are the corresponding electron diffraction patterns taken from areas 1,2 and 3, respectively, in Fig. 6(a). We can readily recognize that there is $2 \mathrm{H}$ martensite in area 1 and 18R martensite in area 2 in Fig. 6(a), since there are diffraction spots at the " $1 / 2$ " and " $1 / 3$ " positions in the row of $001^{*}$ reflections in the corresponding patterns, as indicated by the double arrows in Figs. 6(b) and (c), respectively. Many more stacking faults are found on (001) basal planes within $18 \mathrm{R}$ martensite platelets than

Table 1 Twinning elements of twinning modes in $2 \mathrm{H}$ and $18 \mathrm{R}$ martensites in Ti-Pd alloy.

\begin{tabular}{|c|c|c|c|c|c|}
\hline & $\mathbf{K}_{1}$ & $\eta_{1}$ & $\mathbf{K}_{2}$ & $\eta_{2}$ & $\mathbf{S}$ \\
\hline \multicolumn{6}{|c|}{$2 \mathrm{H}$ martensite } \\
\hline Type I & $\{111\}$ & $\langle\overline{0.671} 1 \overline{0.329}\rangle$ & $\left\{\begin{array}{lll}\overline{1} & 0.678 & 0.356\end{array}\right\}$ & $\langle 121\rangle$ & 0.361 \\
\hline Compound & $\{101\}$ & $\langle\overline{1} 0 \overline{1}\rangle$ & $\{\overline{1} 0 \overline{1}\}$ & $\langle 101\rangle$ & 0.140 \\
\hline \multicolumn{6}{|c|}{ 18R martensite } \\
\hline Type I & $\{12 \overline{8}\}$ & $\left\langle\begin{array}{llll}\overline{1} & 0.776 & 0.069\end{array}\right.$ & $\left\{\begin{array}{llll}\overline{1} & 1.566 & 4.092\end{array}\right\}$ & $\left\langle\begin{array}{lll}10 & 9 & \overline{1}\end{array}\right\rangle$ & 0.366 \\
\hline Type II & $\left\{\begin{array}{lll}\overline{1} & 1.566 & 4.092\end{array}\right\}$ & $\left\langle\begin{array}{lll}10 & 9 & \overline{1}\end{array}\right\rangle$ & $\{12 \overline{8}\}$ & $\left\langle\begin{array}{llll}1 & 0.776 & 0.069\end{array}\right.$ & 0.366 \\
\hline Compound & $\left\{\begin{array}{lll}1 & 0 & 10\end{array}\right\}$ & $\left\langle\begin{array}{lll}\overline{10} & 0 & 1\end{array}\right\rangle$ & $\{\overline{1} 08\}$ & $\langle 801\rangle$ & 0.085 \\
\hline
\end{tabular}
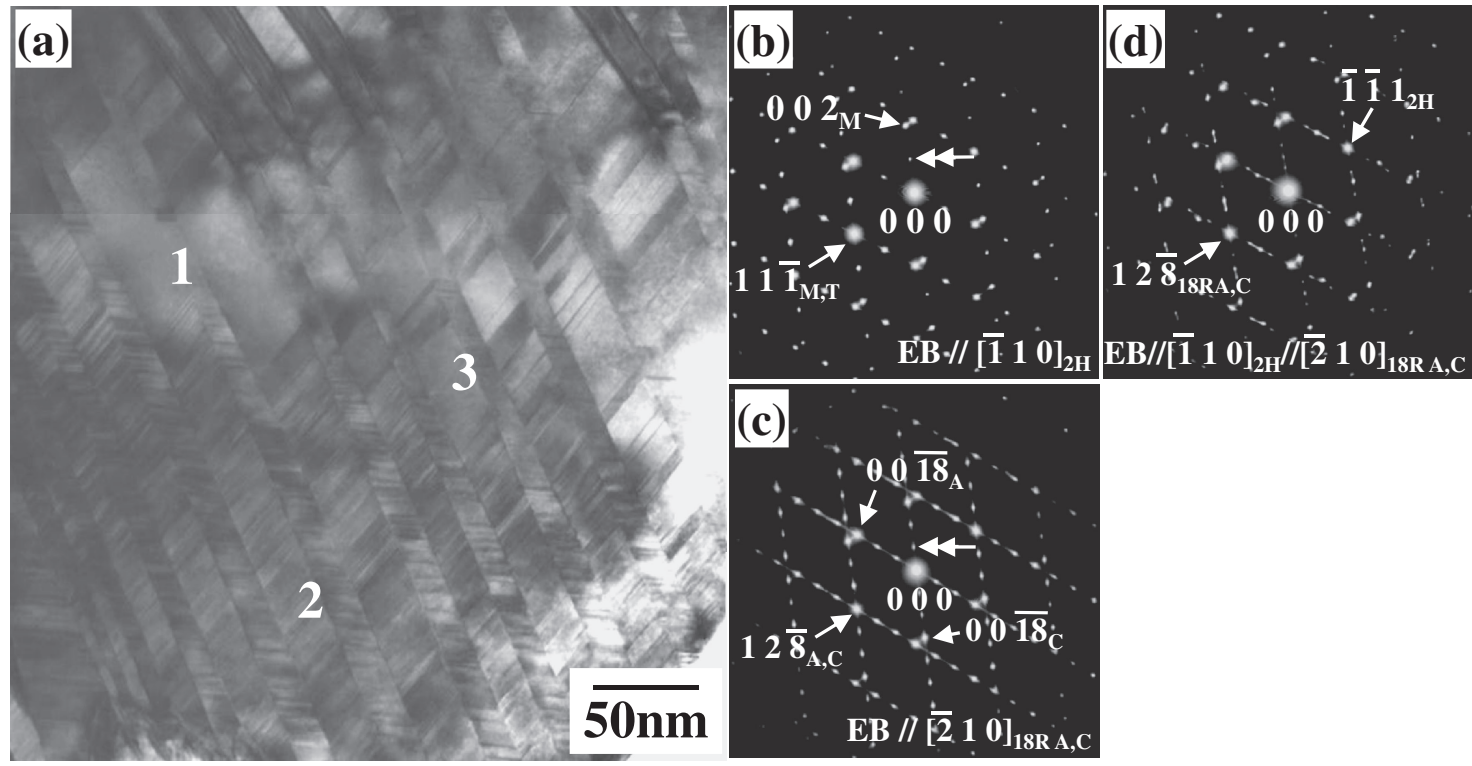

Fig. 6 (a) A bright field image of a "two-in-one" structure. (b) to (d) Corresponding electron diffraction patterns taken from areas 1, 2 and 3 , respectively. 
within the $2 \mathrm{H}$ plateles. The alternating platelets in $2 \mathrm{H}$ and 18R martensites were identified as $(11 \overline{1})_{2 \mathrm{H}}$ and $(12 \overline{8})_{18 \mathrm{R}}$ Type I twinning, respectively, from the patterns in Figs. 6(b) and (c), respectively. Figure $6(\mathrm{~d})$ shows that both the $2 \mathrm{H}$ and $18 \mathrm{R}$ structures are present, and there is therefore a boundary between the $2 \mathrm{H}$ and $18 \mathrm{R}$ martensites. Because the twinning planes of both martensites are originally derived from $\{110\}_{B 2}$ plane, the parallel continuation of those, i.e. $\{11 \overline{1}\}_{2 \mathrm{H}} / /\{12 \overline{8}\}_{18 \mathrm{R}}$, is quite natural. However, there is no clear boundary, such as the zigzag morphology observed between the $2 \mathrm{H}$ and $9 \mathrm{R}$ martensites of Ti-Pd-Fe alloy ${ }^{14,15}$ or between the $2 \mathrm{H}$ and the six layer martensite of Ti-Pt alloy, ${ }^{16}$ ) anywhere in the present observations. In other words, the present $2 \mathrm{H}$ and $18 \mathrm{R}$ martensite continuously connect to each other without a zigzag morphology with compound twinning. ${ }^{14,15)}$ Further studies are required to clarify the nature of the boundary in the two-in-one morphology.

\subsection{Phase transformation at high temperature}

As discussed above, we have shown that an 18R martensite is formed in equiatomic Ti-Pd alloy on quenching at above $1373 \mathrm{~K}$. It is therefore likely that the crystal structure of martensite will depend on the solution treatment temperature. This suggests that a change in structure of the parent phase, such as an order-disorder transformation, occurs at around $1373 \mathrm{~K}$. For example, the disordered and ordered parent phases in Fe-Pt alloy are transformed into bcc and bct martensite, respectively. ${ }^{17,18)}$ The type of the martensitic transformation changes from a non-thermoelastic to a thermoelastic transformation with an increasing degree of order of the parent phase. The Fe-Pd alloy undergoes a thermoelastic transformation from a disordered fcc structure into an fct structure, and the fct martensite phase is further transformed non-thermoelastically into a bct martensite phase. ${ }^{19,20)}$ We therefore examined the possibility of a phase transformation in the present Ti-Pd alloy at above $1273 \mathrm{~K}$, because only the $2 \mathrm{H}$ martensite has been observed in specimens quenched from $1273 \mathrm{~K}^{2-4)}$

Figure 7 shows the DSC heating curve of equiatomic Ti$\mathrm{Pd}$ alloy homogenized at $1273 \mathrm{~K}$. There is an endothermic peak around $830 \mathrm{~K}$ that corresponds to the reverse martensitic transformation. It is noteworthy that some broad endothermic peaks are also observed in the heating curve. Although we cannot explain the origin of these peaks at present, the small endothermic peak near the quenching temperature suggests that a structural change occurs near this temperature, above which the crystal structure of martensite changes as shown by the arrow in Fig. 7. It has been reported that broad endothermic peaks appear in the DSC curves of Ti-Pd-Ni alloy in the temperature range above the reverse martensitic transformation temperature, and these peaks have been attributed to an order-disorder transformation. ${ }^{21)}$ It is wellknown that disordering during heating corresponds to an endothermic peak in DSC curve. ${ }^{22)}$ Furthermore, the latent heat for the order-disorder transformation is much lower than that for the martensitic transformation. There may, therefore, be an order-disorder like transformation at above $1373 \mathrm{~K}$ in the present Ti-Pd alloy. It has been reported that the disordered $\beta$ (bcc) phase transforms in Cu-Al-Mn alloys into a disordered $\alpha^{\prime}$ (fcc) martensite and that the ordered $\beta_{1}\left(\mathrm{DO}_{3}\right)$

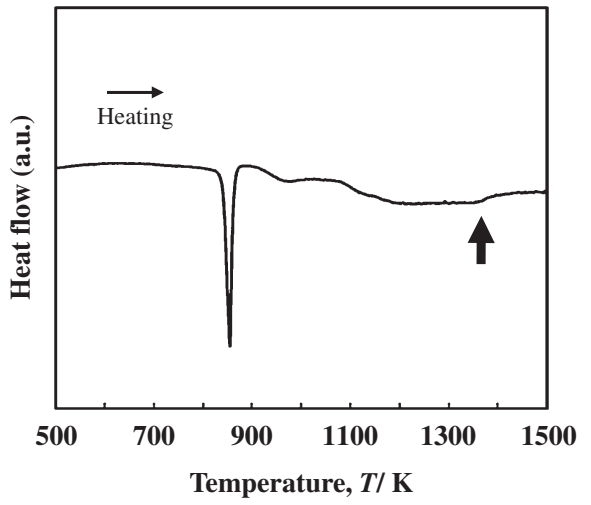

Fig. 7 DSC heating curve for equiatomic Ti-Pd alloy homogenized at $1273 \mathrm{~K}$.

phase transforms into $\beta_{1}{ }^{\prime}$ (18R) martensite. ${ }^{23)}$ That is to say, the ordering of the parent phase normally tends to transform into martensite with a long period stacking structure. This is the opposite tendency to that observed with the present Ti-Pd alloy.

On the basis of the martensitic transformations of Ti-Pd-Fe and Ti-Pt alloys, we expect that Ti-noble metal alloys would tend to undergo a thermoelastic martensitic transformation from B2 to a long period stacking structure. It has been reported that the six layer martensite of Ti-Pt alloy is induced by ion-milling. ${ }^{24)}$ In the present study, the TEM specimens produced by ion-milling of the Ti-Pd alloy quenched below $1273 \mathrm{~K}$ consisted exclusively of $2 \mathrm{H}$ martensite at room temperature, whereas $18 \mathrm{R}$ martensite was formed by quenching above $1373 \mathrm{~K}$. Therefore, the formation of $18 \mathrm{R}$ martensite is not considered to be caused by ion-milling, but the result of a structural change in the parent phase. We need to perform further studies on the phase transformation at high temperatures.

\section{Conclusions}

The morphology and crystallography of the martensite plate with long period stacking structure in Ti-Pd shape memory alloy were investigated by CTEM and HRTEM. The obtained results can be summarized as follows.

(1) In addition to $2 \mathrm{H}$ martensite, an $18 \mathrm{R}(2 \overline{1})_{6}$ structure was observed in equiatomic Ti-Pd alloy quenched at above $1373 \mathrm{~K}$. The lattice parameters of the $18 \mathrm{R}$ martensite are $a=0.49 \mathrm{~nm}, b=0.57 \mathrm{~nm}, c=4.25 \mathrm{~nm}$, and $\beta=$ $84^{\circ}$.

(2) Three fundamental plate variant combinations were identified in the plate group in the region consisting exclusively of $18 \mathrm{R}$ martensite. These were designated $\mathrm{A}: \mathrm{B}, \mathrm{A}: \mathrm{C}$, and $\mathrm{A}: \mathrm{D}$ types, which correspond to

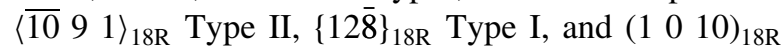
compound twins, respectively. Their morphologies are of the wedge, spear and fork types, respectively.

(3) The duplex martensitic phases coexist within the same area; in other words, a "two-in-one" morphology was observed. A parallel continuation of the twinning plates of both martensites, i.e. $\{11 \overline{1}\}_{2 \mathrm{H}} / /\{12 \overline{8}\}_{18 \mathrm{R}}$, was also seen. 
(4) During heating, a small endothermic peak in the DSC curve was observed at around $1370 \mathrm{~K}$. This suggests that there is probably some kind of phase transformation, such as disordering, because the stacking sequence of the resultant martensite quenched above $1373 \mathrm{~K}$ is changed from $2 \mathrm{H}$ to $18 \mathrm{R}(2 \overline{1})_{6}$.

\section{Acknowledgments}

This study was supported by a "Grant-in-Aid for Scientific Research (B)" from the Japanese Society for the Promotion of Science (JSPS)" and a "Grant-in-Aid for Young Scientists (B)" from the Ministry of Education, Culture, Sports, Science and Technology (MEXT), Japan. The authors would like to express their sincere appreciation to Prof. R. Kainuma and Dr. M. Nagasako of Tohoku University for their support in the DSC measurements and for their valuable comments.

\section{REFERENCES}

1) H. C. Donkersloot and J. H. N. Van Vucht: J. Less-Common Met. 20 (1970) 83-91.

2) K. Enami, H. Seki and S. Nenno: Tetsu-to-Hagane. 72 (1986) 563-570.

3) M. Nishida, T. Hara, Y. Morizono, A. Ikeya, H. Kijima and A. Chiba: Acta Mater. 45 (1997) 4847-4853.

4) M. Nishida, T. Hara, M. Matsuda and S. Ii: Mater. Sci. Eng. A 481-482 (2008) 18-27.

5) T. Yamamuro, Y. Morizono, J. Honjyo and M. Nishida: Mater. Sci. Eng. A 438-440 (2006) 327-331.

6) Z. Nishiyama: Martensitic Transformation, (Academic Press, New York, 1978).

7) H. Tas, L. Delaey and A. Deruyettre: Metall. Trans. A 4 (1973) 2833-
2840.

8) T. A. Schroeder and C. M. Wayman: Acta Metall. 25 (1977) 13751391.

9) T. Saburi and C. M. Wayman: Acta Metall. 27 (1979) 979-995.

10) Y. Murakami, K. Otsuka, S. Hanada and S. Watanabe: Mater. Sci. Eng. A 189 (1994) 191-199.

11) K. Adachi, J. Perkins and C. M. Wayman: Acta Metall. 34 (1986) 2471-2485.

12) A. E. Dwight, R. A. Conner and J. W. Downey: Acta Crystallogr. 18 (1965) 835-839.

13) B. A. Bilby and A. G. Crocker: Proc. R. Soc. London, Ser. A 288 (1965) 240-255.

14) K. Enami and Y. Nakagawa: Proc. Int. Conf. on Martensitic Transformations (ICOMAT-92), ed. by C. M. Wayman and J. Perkins, (Monterey Institute of Advanced Studies, Monterey, California, 1993) pp. 521-526.

15) S. Ii, M. Nishida, T. Hara and K. Enami: Mater. Trans. 43 (2002) 902907.

16) M. Nishida, M. Matsuda, Y. Yasumoto, S. Yano, Y. Yamabe-Mitarai and T. Hara: Mater. Sci. Technol. 24 (2008) 884-889.

17) D. P. Dunne and C. M. Wayman: Metall. Trans. 4 (1973) 137-145.

18) S. Muto, R. Oshima and F. E. Fujita: Metall. Trans. A 19 (1988) 27232731.

19) T. Sohmura, R. Oshima and F. E. Fujita: Scr. Metall. 14 (1980) 855856.

20) M. Sugiyama, R. Oshima and F. E. Fujita: Trans. Jpn. Inst. Met. 25 (1984) 585-592.

21) Ya. Xu, S. Shimizu, Y. Suzuki, K. Otsuka, T. Ueki and K. Mitose: Acta Mater. 45 (1997) 1503-1511.

22) R. Kainuma, N. Satoh, X. J. Liu, I. Ohnuma and K. Ishida: J. Alloy. Compd. 266 (1998) 191-200.

23) R. Kainuma, S. Takahashi and K. Ishida: Metall. Mater. Trans. A 27 (1996) 2187-2195.

24) G. M. Rotaru, W. Tirry, P. Sittner, J. V. Humbeeck and D. Schryvers: Acta Mater. 55 (2007) 4447-4454. 